\title{
Phospholipid-mediated Delivery of Anti-GAP-43 Antibodies into Neuroblastoma Cells Prevents Neuritogenesis
}

\author{
Thomas B. Shea, ${ }^{1,2}$ Nora I. Perrone-Bizzozero, ${ }^{1,2}$ Mary Lou Beermann,' and Larry I. Benowitz \\ 'Mailman Research Center, McLean Hospital, Belmont, Massachusetts 02178 and ${ }^{2}$ Department of Psychiatry and \\ 3Program in Neuroscience, Harvard Medical School, Boston, Massachusetts 02115
}

\begin{abstract}
The neuronal growth-associated protein GAP-43 is expressed during axonal outgrowth and regeneration (for review, see Benowitz and Routtenberg, 1987). In the present study, we demonstrate that GAP-43 is constitutively expressed by NB2a/d1 neuroblastoma cells. The initial, most rapid outgrowth period of neuritogenesis $[0-4 \mathrm{hr}$ after dibutyryl adenosine $3^{\prime}, 5^{\prime}$-cyclic monophosphate (dbcAMP) treatment] is accompanied by intense GAP-43 immunoreactivity along the entire length of most neurites. However, this immunoreactivity declined nearly to background levels within hours during continued neurite outgrowth and persisted only at varicosities and growth cones. GAP-43 was detectable by metabolic labeling and immunoblot analysis in undifferentiated cells, and synthetic rates and steady-state levels of GAP-43 underwent only a modest (approximately twofold) increase during dbcAMP-induced differentiation. Unlike levels observed in neurites, perikarya of undifferentiated and differentiated cells contained similar, intense levels of GAP-43 immunoreactivity. Neurite elaboration and GAP-43 immunoreactivity were unaffected by treatment with cycloheximide, suggesting that translocation of perikaryal GAP-43 pools, rather than de novo synthesis, contributes to the transient burst of GAP-43 observed in developing neurites. Phosphatidylcholine-mediated delivery of anti-GAP-43 antibodies ( $\alpha$ GAP) into cells immediately before dbcAMP treatment arrested neuritogenesis but did not induce the retraction of existing neurites. These results indicate that, while GAP-43 expression is insufficient to induce neuritogenesis in NB2a/d1 cells, GAP-43 is nevertheless essential for the initial, dynamic phase of neurite outgrowth.
\end{abstract}

The development and restructuring of neuronal connections involve the coordinate expression of numerous cellular constituents, one of which is the membrane-associated phosphoprotein GAP-43 (also known as B50, F1, pp46, GAP48, p57, neuromodulin; Benowitz and Routtenberg, 1987; Skene, 1989). Neurons express high levels of this protein during axogenesis and synaptogenesis, at which time it is abundant along the entire

\footnotetext{
Received Oct. 18, 1990; revised Dec. 31, 1990; accepted Jan. 9, 1991.

This research was supported by National Science Foundation Grant BNS8910869 , by National Eye Institute Grant EY 05690 , by National Institute of Neurological Disease and Stroke Grant NS25830, and by the Scottish Rite Foundation.

Correspondence and reprint requests should be addressed to Thomas B. Shea, Ph.D., Mailman Research Center, McLean Hospital, Belmont, MA 02178. Additional correspondence may be addressed to Larry I. Benowitz, Ph.D., Neurosurgery, Children's Hospital, 300 Longwood Avenue, Boston, MA 02178.

Copyright @ 1991 Society for Neuroscience 0270-6474/91/111685-06\$03.00/0
}

axonal length and in growth cones (Meiri et al., 1988; Moya et al., 1989; Dani et al., 1990; Goslin et al., 1990b). Axonal regeneration and reactive synaptogenesis are likewise marked by a resurgence of GAP-43 expression (Benowitz and Routtenberg, 1987; Skene, 1989; Benowitz et al., 1990). Although overall levels of this protcin decline sharply in most of the brain following the establishment of mature synapses (Jacobson et al., 1986; McGuire et al., 1988), certain brain regions continue to have considerable levels of GAP-43 throughout life (Gispen et al., 1985; Nelson et al., 1987; Benowitz et al., 1988; Neve et al., 1988), where its presence has been linked to signal transduction mechanisms that regulate the function and structure of presynaptic endings (Jolles et al., 1980; Lovinger et al., 1985; Alexander et al., 1987; Freeman et al., 1988; Dekker et al., 1989).

With regard to the causal role of this protein in axonal outgrowth, transfection of the GAP-43 gene has been reported to increase the extension of filopodial processes in Cos cells (Zuber et al., 1989) and to accelerate the NGF-mediated outgrowth of neurites and increase sensitivity to NGF in PC12 pheochromocytoma cells (Yankner et al., 1990). However, in transformed cell lines of embryonic brain origin, though GAP-43 is constitutively expressed, neuritogenesis does not occur spontaneously and requires the addition of other agents (Megerian et al., 1989). To investigate further the role of GAP-43 expression in neurite outgrowth, we used L- $\alpha$-lysophosphaditylcholine (LPC; Nomura et al., 1986; Shea and Beermann, 1991) to introduce anti-GAP43 antibodies into NB2a/d 1 neuroblastoma, a cell line that elaborates axonal processes following treatment with dibutyryl cAMP and other agents (Shea et al., 1985, 1988, 1991a). Our results indicate that, though GAP-43 expression by itself is not sufficient to cause NB2a/dl cells to extend neurites, in conjunction with other factors it is required for axonal outgrowth to occur.

Portions of this research have been presented in abstract form (Shea et al., 1991b).

\section{Materials and Methods}

Cell culture. NB2a/dl cells (Shea et al., 1985) were cultured and induced to extend axonal neurites by the addition of $1 \mathrm{~mm}$ dibutyryl adenosine $3^{\prime}, 5^{\prime}$-cyclic monophosphate (dbcAMP; Sigma Chemical Co.) or serum deprivation as described previously (Shea et al., 1985, 1988) $24 \mathrm{hr}$ after the initial plating for $0,4,24$, or $72 \mathrm{hr}$. Cycloheximide $(0.5 \mu \mathrm{g} / \mathrm{ml}$; Sigma) was added to some cultures $90 \mathrm{~min}$ before dbcAMP.

Quantitation of neurite outgrowth. At 4 or $24 \mathrm{hr}$ after the above treatments, duplicate cultures were rinsed in Tris-buffered saline (TBS; $\mathrm{pH}, 7.4$ ), fixed for $10 \mathrm{~min}$ in $4 \%$ paraformaldehyde in $0.1 \mathrm{~m}$ phosphate buffer $(\mathrm{pH}, 7.2)$ at room temperature for $15 \mathrm{~min}$, then rinsed and stored in TBS. All experiments were carried out at least twice. In each experiment, between 100 and 200 cells in each of the fixed cultures were examined by phase-contrast microscopy. The relative extent of neurite 
Figure 1. NB2a/d1 cells extend neurites within a few hours of dbcAMP treatment, and this does not appear to require the synthesis of new proteins. Cells were treated with $1 \mathrm{~mm}$ dbcAMP for $0(A), 4(B), 24(C)$, or $72 \mathrm{hr}(D)$. Cycloheximide had no detectable effect on initial $(4 \mathrm{hr})$ neurite outgrowth $(E)$.
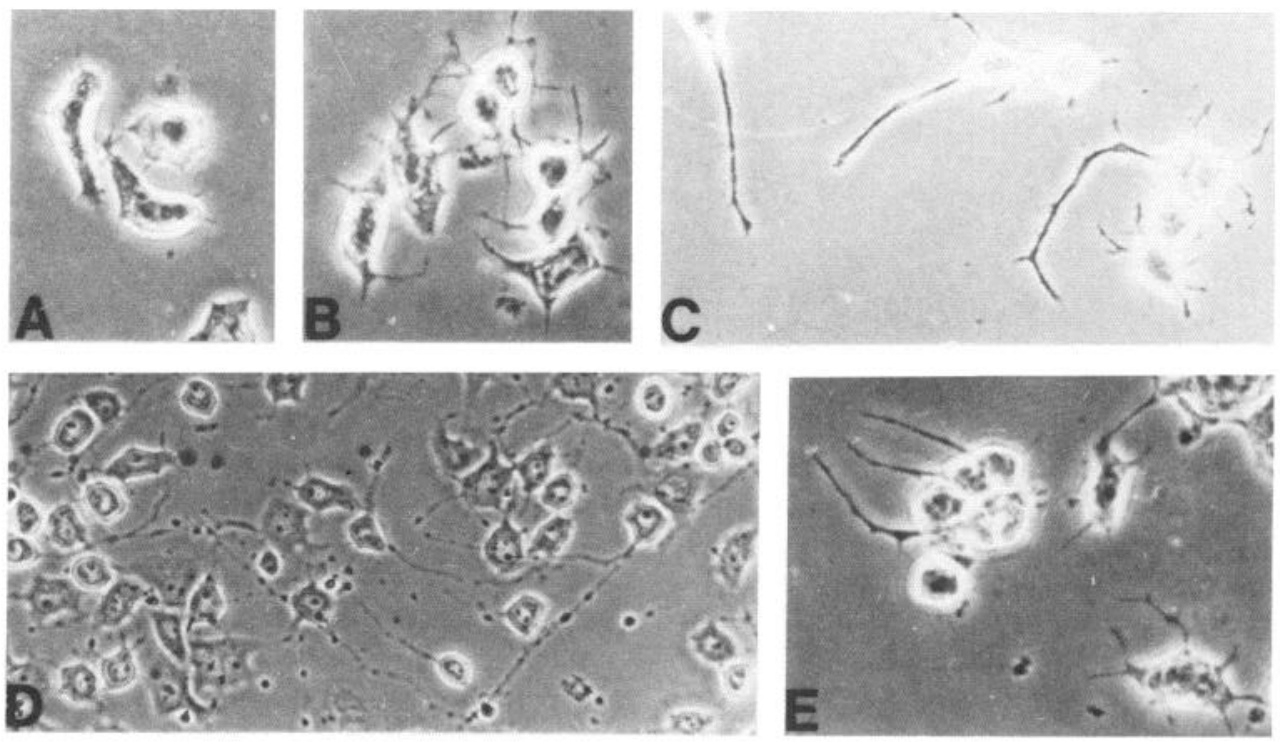

outgrowth was quantitated by comparison of neurite length with respective somal diameter (SD). Previous quantitative studies of NB2a/ dl neurite outgrowth (Shea et al., 1985, 1991b) have shown that the majority of undifferentiated $\mathrm{NB} 2 \mathrm{a} / \mathrm{d} 1$ cells possess putative neurites of $<1 \mathrm{SD}$, while the respective modal length of neurites induced by various treatments is 1-2 SD at $4 \mathrm{hr}$ and $2-3 \mathrm{SD}$ at $24 \mathrm{hr}$. Accordingly, for analyses of neurite induction at $4 \mathrm{hr}$, the percentage of cells per culture with neurites was determined by calculating (mean number of cells with $\geq 1$-SD neurites/mean number of total cells scored) $\times 100$, and the percentage of cells per culture with neurites at $24 \mathrm{hr}$, by calculating (mean number of cells with $\geq 2$-SD neurites/mean number of total cells scored) $\times 100$ as described previously (Shea et al., 1991b). Ratios of cells with or without neurites were statistically compared by Student's $t$ test.
Immunocytochemistry. Cultures were fixed with $4 \%$ paraformaldehyde and reacted with a 1:1000 dilution of the IgG fraction derived from a sheep polyclonal antibody directed against GAP-43 or the respective preimmune IgG fraction ( $\alpha$ GAP; Benowitz et al., 1988) followed by a 1:1000 dilution of a biotinylated goat anti-sheep antibody (ICN Immunochemicals, Naperville, MD), then stained with the avidinbiotin complex (ABC) conjugated to horseradish peroxidase and diaminobenzidine (Sigma) as described (Shea et al., 1988).

Gel electrophoresis and immunoblot analysis. Triton-soluble proteins from undifferentiated cultures and cultures treated with dbcAMP for $24 \mathrm{hr}(200 \mu \mathrm{g})$ were electrophoresed on SDS-6\% polyacrylamide gels, transferred to nitrocellulose, reacted with a monospecific antibody to GAP-43 (at a 1:2000 dilution in Tris-buffered saline overnight at room temperature), and visualized as described (Shea et al., 1988).
Figure 2. GAP-43 is expressed constitutively in NB2a/dl cells and is abundant in newly growing neurites. Cells were treated with $1 \mathrm{~mm}$ dbcAMP for $0(a), 4(b), 12(c), 16(d)$, and $24 \mathrm{hr}$ $(e)$, after which cultures were fixed and immunostained with $\alpha \mathrm{GAP}$. Whereas the filopodia-like neurites of untreated cells are unstained (arrows, $a$ ), dbcAMP-induced neurites show intense staining for GAP-43 along their entire length by $4 \mathrm{hr}$, after which levels remain intense only in select varicosities (arrows, $c-e$ ) or growth cones (arrowheads, $c$ and $d$ ). Perikaryal staining, by contrast, is high even in untreated cells and does not change appreciably during differentiation $(a-e)$.

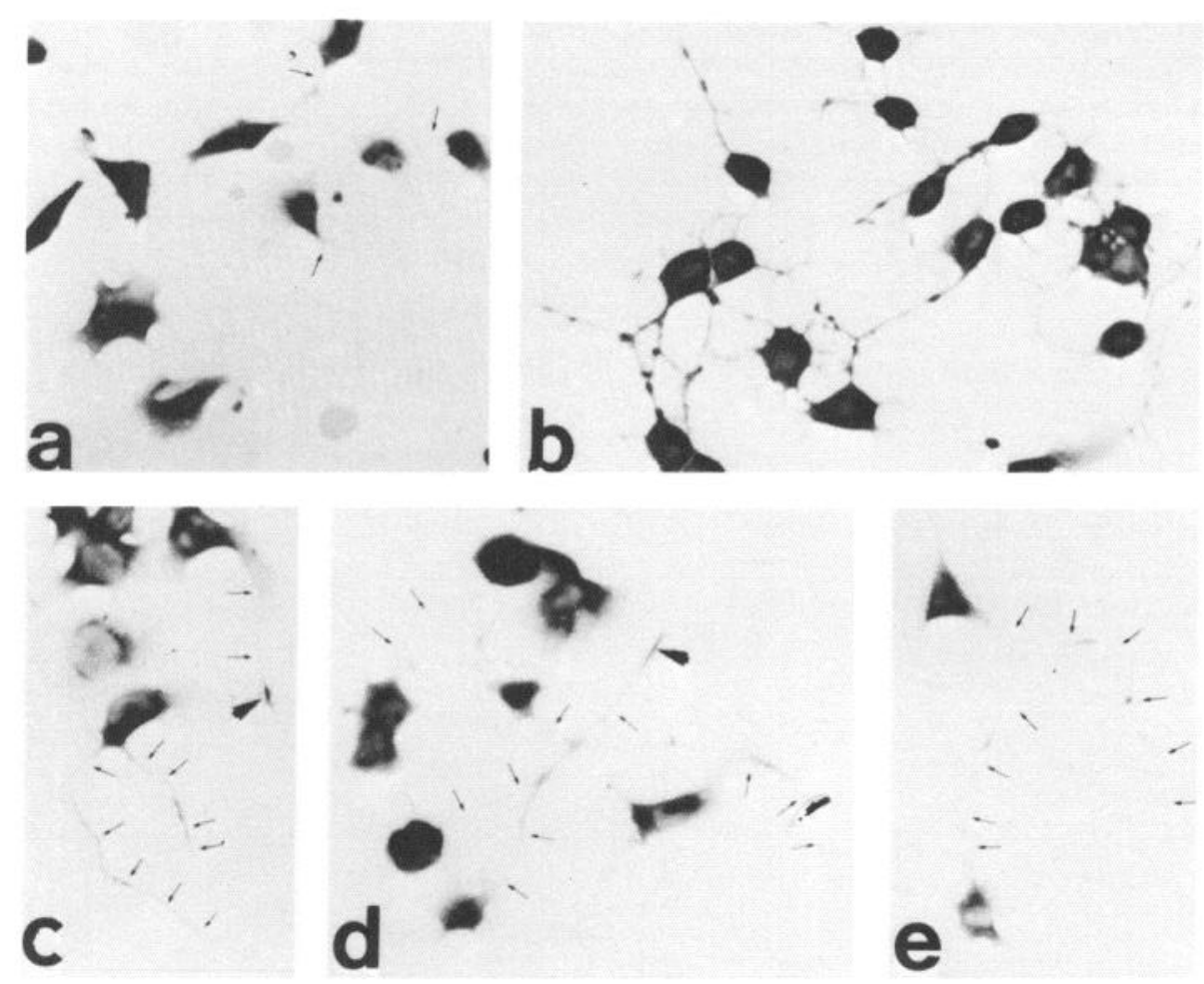




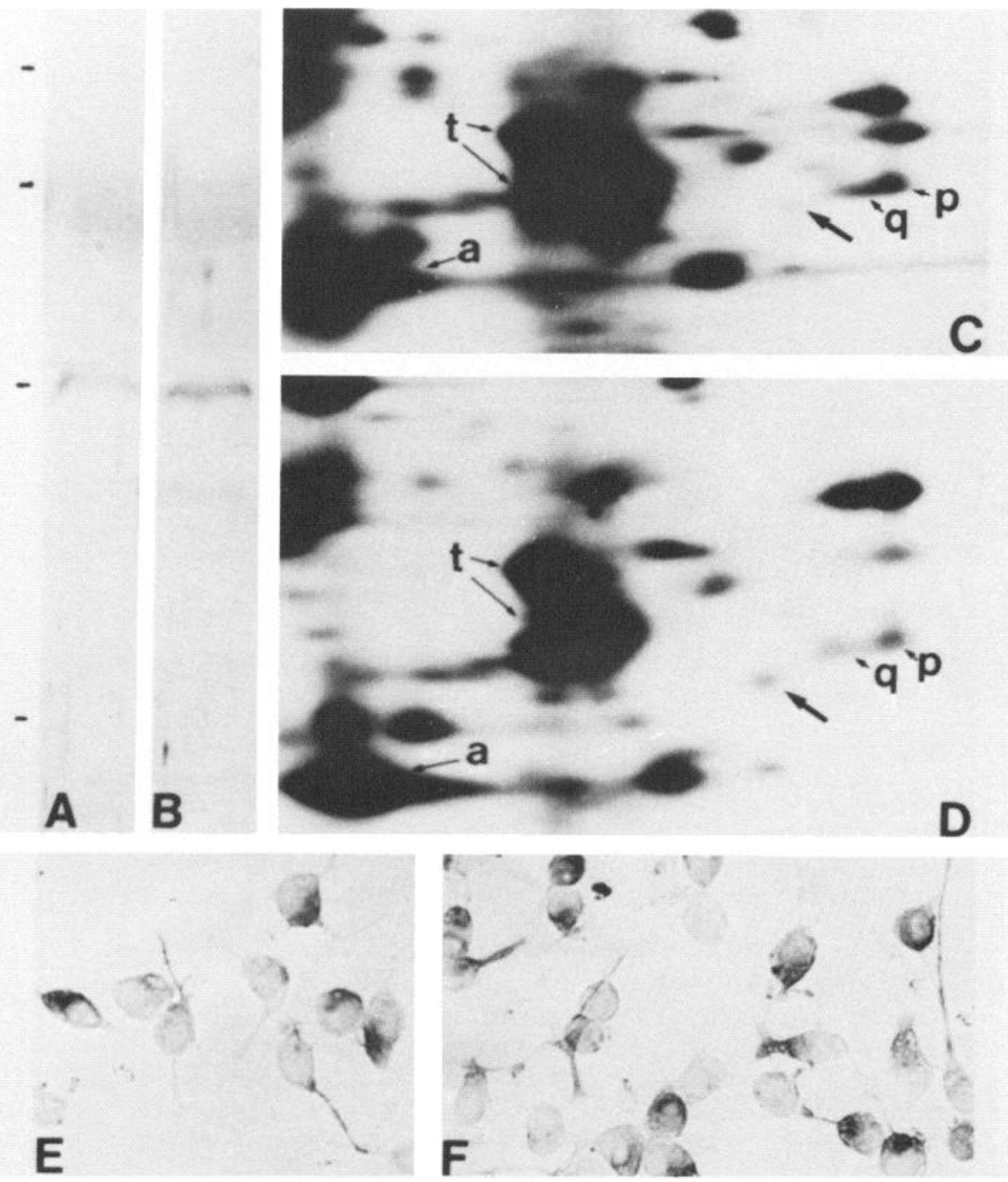

Figure 3. Effect of dbcAMP on GAP43 expression and translocation into neurites. $A$ and $B$, Western blots showing levels of GAP-43 in control and in differentiated cultures. GAP-43 (migrating with an apparent molecular weight of $45 \mathrm{kDa}$ ) is present even prior to the induction of neurites $(A)$, and levels increase only about twofold after treatment with dbcAMP $(B)$. Molecular weight markers are at $97,66,45$, and $30 \mathrm{kDa}$. $C$ and $D$, Levels of GAP-43 synthesis in control and differentiated cultures. GAP-43 (large arrows: $M_{r} \mathbf{4 5}$ $\mathrm{kDa}, \mathrm{pI} 4.7)$ is synthesized in control cultures $(C)$ and increases only somewhat with dbcAMP treatment $(D)$. Other proteins indicated as reference points: $t, \alpha$ - and $\beta$-tubulins; $a$, actin; $p$ and $q$, polypeptides previously described in cerebrocortical neuronal cultures (Perrone-Bizzozero et al., 1986). $E$ and $F$, Immunocytochemical analyses of GAP43 distribution after $4 \mathrm{hr}$ of dbcAMP treatment in the absence $(E)$ and presence $(F)$ of cycloheximide. Neither neuritogenesis nor the appearance of GAP43 immunoreactivity within neurites appears to be affected by the inhibition of protein synthesis (see also Fig. 1E).

Radiolabeling. NB2a/dl cells were radiolabeled in vivo for $4 \mathrm{hr}$ with a mixture of ${ }^{35} \mathrm{~S}$-methionine plus cysteine (Trans- ${ }^{35} \mathrm{~S}$, ICN, Irvine, CA), and the patterns of protein labeling were visualized on 2-D gel fluorograms as described (Perrone-Bizzozero et al., 1986; Shea et al., 1988). Quantitation of radiolabel incorporated into individual proteins was carried out using the Visage-100 computer densitometry system as described (Fischer and Shea, 1991).

Permeabilization of cells and intracellular delivery of antibody. Antibodies were loaded into cells by the procedure of Nomura et al. (1986) as modified by Shea and Beermann (1991). Cells (50-75\% confluent) in $35-\mathrm{mm}^{2}$ Petri dishes were rinsed with serum-free Dulbecco's modified Eagle's medium (DMEM) and treated with $1 \mathrm{ml}$ prewarmed $\left(37^{\circ} \mathrm{C}\right) 1.2$ $\mathrm{m}$ glycerol in phosphate-buffered saline $(\mathrm{pH}, 7.4)$. Cells were then incubated at $0^{\circ} \mathrm{C}$ for $10 \mathrm{~min}$ (by placing the culture plates directly on ice), after which L- $\alpha$-lysophosphatidylcholine (LPC; Sigma Chemical Co.) was added to a final concentration of $40 \mu \mathrm{g} / \mathrm{ml}$, and the incubation continued for an additional $8 \mathrm{~min}$. One milliliter of prewarmed $\left(37^{\circ} \mathrm{C}\right)$ serum-free DMEM containing no antibody or 1:20 dilutions of $\alpha \mathrm{GAP}$, a polyclonal antibody raised in this laboratory against the high-molecular-weight neurofilament subunit $(\alpha \mathrm{NF}-\mathrm{H})$ or their respective preimmune sera, were then added to cultures incubating with the glycerolLPC solution, and the cultures were immediately returned to the $37^{\circ} \mathrm{C}$ incubator for $10 \mathrm{~min}$. Cells regained impermeability during this incubation, as ascertained by the recovery of trypan blue exclusion (Shea and Beermann, 1991). Cultures then received an additional $1 \mathrm{ml}$ of prewarmed medium containing $10 \%$ horse serum and dbcAMP and were incubated for $4 \mathrm{hr}$, after which they were fixed and examined by phase-contrast microscopy. Loaded cells were not monitored for periods longer than $4 \mathrm{hr}$ due to the likelihood of antibody degradation. Permeabilized cells elaborated neurites following dbcAMP treatment at a rate indistinguishable from nonpermeabilized cells. In all experiments, successful loading of antibody was confirmed by reaction of cells with goat anti-sheep IgG and visualization as described above.

\section{Results}

\section{Expression of $\mathrm{GAP}-43$ by $\mathrm{NB} 2 \mathrm{a} / \mathrm{d} 1$ cells}

$\mathrm{NB} 2 \mathrm{a} / \mathrm{d} 1$ cells elaborate axonal neurites that are detectable within $4 \mathrm{hr}$ after the addition of dbcAMP (Fig. $1 A, B$ ); these neurites continue to elongate over the next $7 \mathrm{~d}$, though at a slower rate (Fig. 1C,D). Inhibition of protein synthesis by cycloheximide treatment does not interfere with neuritogenesis (Fig. 1E), in agreement with previous observations (Shea et al., 1991a).

NB2a/d1 cells express moderately high levels of GAP- 43 even prior to the induction of neuritogenesis (Figs. 2a, 3A). Treatment with dbcAMP causes only a small overall increase in GAP43 levels, as assessed by immunocytochemistry, Western blots, and protein synthesis (Figs. $2 a-e, 3 A-D$ ). However, with the induction of process outgrowth, high levels of the protein became evident along the entire length of newly growing neurites (Fig. $2 b$ ). GAP-43 levels in newly growing neurites exceed those in the filopodia-like neurites of nontreated cells (Fig. 2a,b). Neu- 

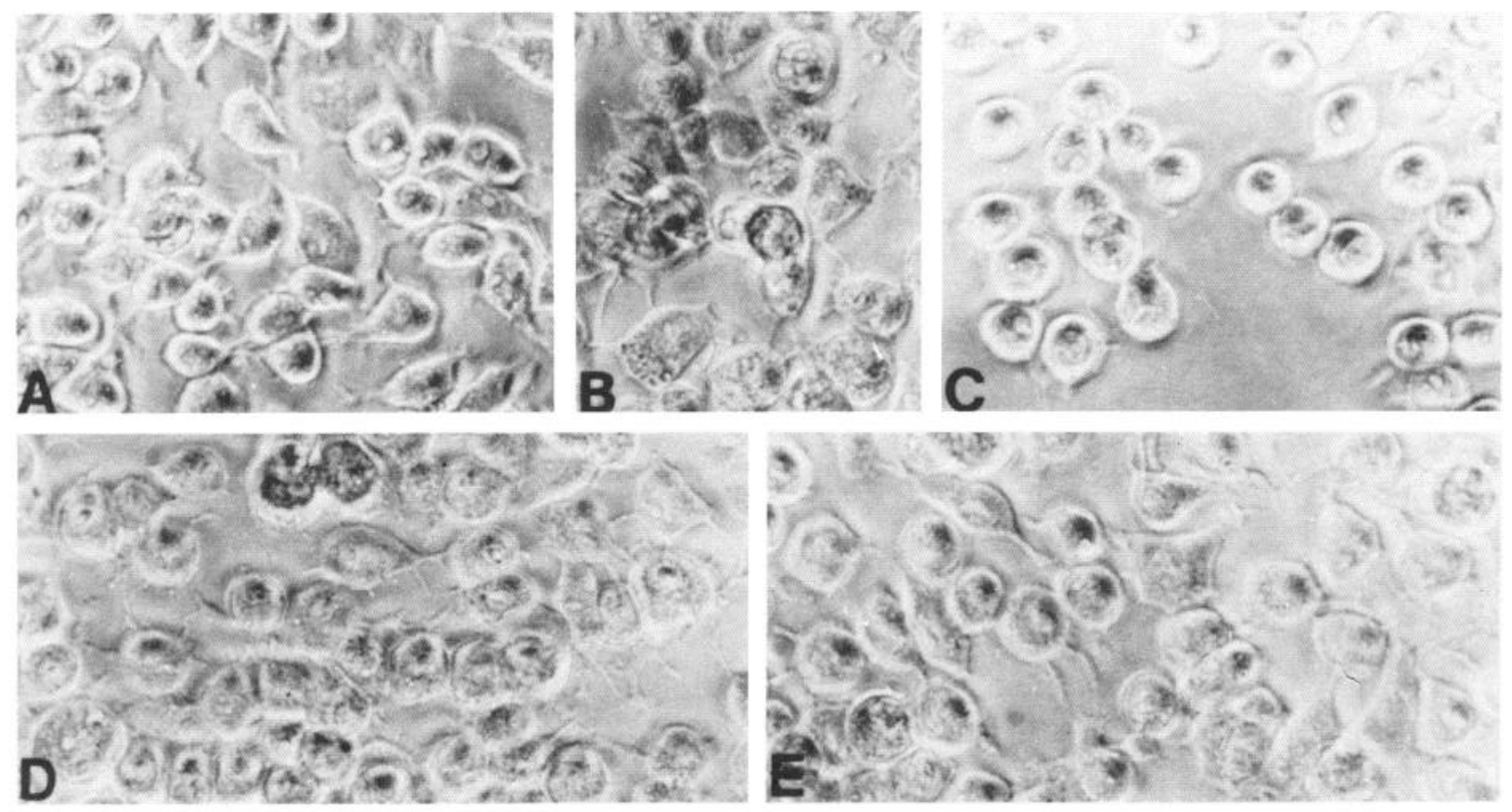

Figure 4. Antibodies to GAP-43 arrest neuritogenesis. Antibodies were loaded into NB2a/d1 cells by the procedure of Nomura et al. (1986) as modified by Shea and Beermann (1991). Permeabilized cells were exposed to no antibody $(A)$ or to 1:20 dilutions of $\alpha$ GAP preimmune serum $(B)$, $\alpha \mathrm{GAP}(C), \alpha \mathrm{NF}-\mathrm{H}$ preimmune serum $(D)$, or $\alpha \mathrm{NF}-\mathrm{H}(E)$, then treated with dbcAMP for $4 \mathrm{hr}$, after which they were fixed and examined by phasecontrast microscopy. Restriction of neuritogenesis and rounding of bodies were found only in cells exposed to $\alpha \mathrm{GAP}(C)$.

rite staining then declines over the next $20 \mathrm{hr}$ of dbcAMP treatment and is quite low at $7 \mathrm{~d}$ (Fig. $2 e$ ). Cycloheximide treatment, which does not interfere with neuritogenesis, does not alter the time course or intensity of GAP-43 immunoreactivity in neurites (Fig. $3 E, F$ ). Thus, at least a portion of the GAP-43 that is seen within newly elaborated neurites must be derived from the pool that is already present within perikarya prior to differentiation; however, as noted previously (Megerian et al., 1989), the presence of this pool is not in and of itself enough to stimulate neurite outgrowth without the addition of other stimulatory factors.

Table 1. Effect of loading of $\alpha \mathrm{GAP}$ and $\alpha \mathrm{NF}-\mathrm{H}$-immune and preimmune sera on NB2a/d1 neuritogenesis

\begin{tabular}{lll} 
Serum loaded & $\begin{array}{l}\text { Length of } \\
\text { dbcAMP } \\
\text { treatment } \\
\text { before loading (hr) }\end{array}$ & Neurite ratio \\
\hline None (control) & 0 & $2.67 \pm 0.39$ \\
GAP-43 preimmune serum & 0 & $2.65 \pm 1.17$ \\
$\alpha$ GAP & 0 & $0.22 \pm 0.10^{*}$ \\
NF-H preimmune serum & 0 & $2.81 \pm 1.16$ \\
$\alpha$ NF-H & 0 & $2.64 \pm 1.02$ \\
GAP-43 preimmune serum & 24 & $2.36 \pm 0.40$ \\
$\alpha$ GAP & 24 & $2.69 \pm 0.90$
\end{tabular}

Transiently permeabilized cells were exposed to 1:20 dilutions of immune or preimmune sera in culture medium at 0 or $24 \mathrm{hr}$ after the induction of axonal neuritogenesis by dbcAMP. All cultures were incubated with dbcAMP for an additional $4 \mathrm{hr}$, then immediately fixed and examined by phase-contrast microscopy. Neurite outgrowth was quantitated as described in Materials and Methods. Values represent the mean \pm standard deviation.

* Statistically different from controls $(p<0.0005)$.
Undifferentiated NB2a/d1 cells continuously extend and retract short filopodia-like neurites (see, e.g., Fig. $2 a$ ), and treatments that induce neurite outgrowth may do so by stabilizing these filopodia and promoting their continued outgrowth (Shea et al., 1991a). To examine whether the basal expression of GAP43 by undifferentiated NB2a/d1 cells was correlated with the elaboration of unstable filopodia-like neurites, cells were cultured in suspension, a condition under which filopodia-like neurites are not elaborated. However, immunoblot analysis and metabolic labeling revealed that suspended and adherent cells expressed similar levels of GAP-43 (not shown).

\section{Role of GAP-43 in axonal outgrowth}

In order to examine whether GAP-43 is required for neuritogenesis to occur, antibodies to the protein were introduced into NB2a/d1 neuroblastoma. The cells were transiently permeabilized in the presence or absence of anti-GAP antibodies ( $\alpha$ GAP), then treated with dbcAMP for $4 \mathrm{hr}$ to induce neuritogenesis. In control cultures loaded with $\alpha \mathrm{GAP}$ preimmune serum, neurite outgrowth was virtually identical to that obtained in the absence of antibody, as measured by the ratio of cells possessing neurites of $\geq 1$ SD compared to those possessing neurites of $<1 \mathrm{SD}$ (Table 1). In contrast, loading cells with $\alpha$ GAP almost completely arrested neurite outgrowth, with an approximately $90 \%$ reduction in this ratio (Table 1, Fig. 4). Moreover, cells loaded with $\alpha \mathrm{GAP}$ actually appeared to be less differentiated than control cells loaded with preimmune or no serum, with substantially less polygonal somata and fewer filopodia (Fig. 4). The effects of the antibody treatment were dose dependent: exposure of permeabilized cells to serial dilutions of $\alpha \mathrm{GAP}$ progressively lessened the inhibitory effect on neuritogenesis; anti-GAP-43 antibodies also inhibited outgrowth of axonal neurites in response to serum deprivation (not shown). Loading of $\alpha \mathrm{GAP}$ at 


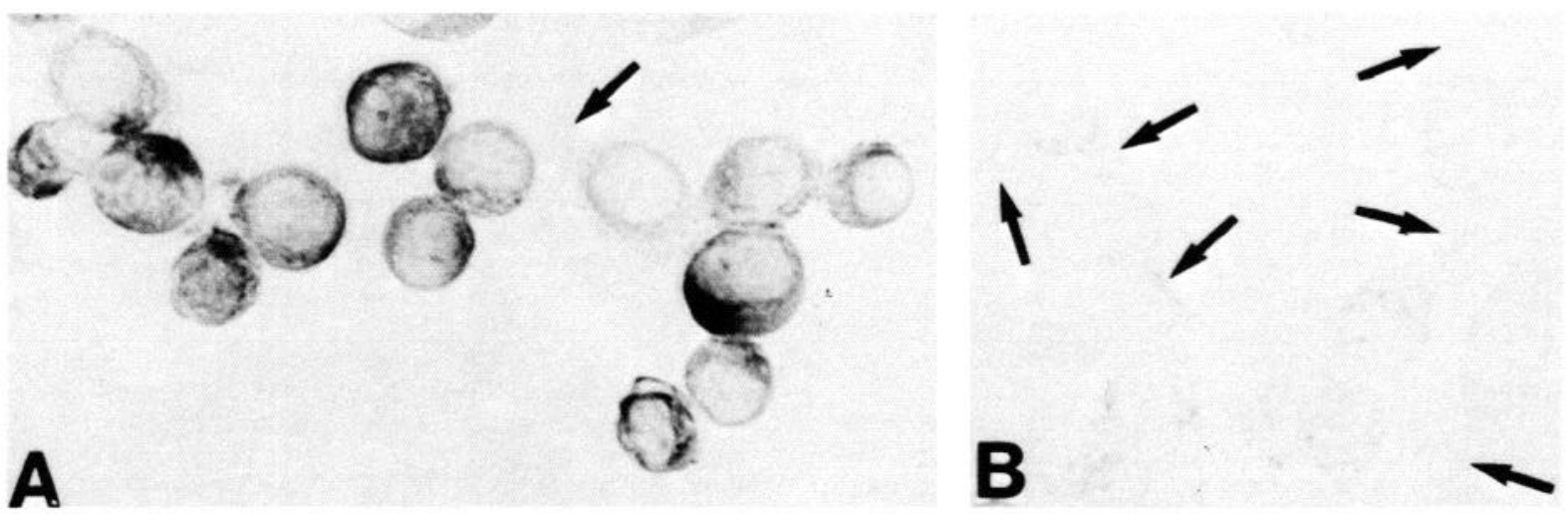

Figure 5. Cytochemical demonstration of antibody uptake. Cells were permeabilized, exposed to $\alpha$ GAP $(A)$ or no antibody $(B)$, treated with dbcAMP for $4 \mathrm{hr}$, fixed and reacted with peroxidase-conjugated goat anti-sheep IgG, and visualized as described in Materials and Methods. Cells exposed to $\alpha$ GAP during permeabilization showed cytoplasmic staining $(A)$ and little neurite outgrowth, whereas cells not exposed to the primary antibody showed little staining and elaborated neurites (arrows, $B$ ). Note that, in $\alpha \mathrm{GAP}$-treated cultures, individual cells that had internalized relatively little $\alpha$ GAP (as evidenced by low staining levels) did show neurite outgrowth (arrow, $A$ ).

$24 \mathrm{hr}$, a time at which GAP-43 levels normally decline and neurite outgrowth slows down, did not cause existing neurites to retract (Table 1). This demonstrates that the antibody does not have general cytotoxic effects on these cells. As an additional control, we used an antibody directed against an extensively phosphorylated form of $\alpha \mathrm{NF}-\mathrm{H}$, a cytoskeletal component that is present in a soluble form in undifferentiated NB2a/d1 cells but not incorporated into the axonal cytoskeleton until $3 \mathrm{~d}$ after the addition of the dbcAMP (Shea et al., 1988). As shown in Figure 4 and in Table 1, $\alpha$ NF-H, unlike $\alpha \mathrm{GAP}$, did not affect neuritogenesis.

To confirm that permeabilized cells had successfully taken up antibodies, cultures that had been treated with $\alpha \mathrm{GAP}$ after LPC were reacted with a biotinylated goat anti-sheep antibody, then stained with $\mathrm{ABC}$ conjugated to HRP and diaminobenzidine. This procedure also afforded the opportunity to examine whether the internalization of $\alpha \mathrm{GAP}$ correlated with the arrest of neurite outgrowth in individual cells. As shown in Figure 5, NB2a/d1 cells that internalized significant levels of $\alpha$ GAP showed little differentiation, whereas cells with relatively little primary antibody did elaborate neurites (Fig. 5). Exposure of cells to $\alpha \mathrm{GAP}$ without permeabilization did not affect neuritogenesis, nor did it result in specific cytochemical staining (not shown).

\section{Discussion}

It has been proposed that GAP-43 participates in neuritogenesis by altering the rate at which new membrane is added to growth cones (Meiri et al., 1988; Gordon-Weeks, 1989). The observation that GAP-43 levels in neurites are maximal at the time at which outgrowth is occurring, that is, within the first few hours of dbcAMP treatment (Shea et al., 1985), is consistent with this hypothesis. Moreover, the observations that neurites at later time points have much lower levels of GAP-43 and that the introduction of $\alpha \mathrm{GAP}$ does not cause existing neurites to retract suggest that GAP-43 is particularly involved in the initial, active phase of neurite outgrowth. Because continued neurite elongation has slowed dramatically by $24 \mathrm{hr}$ of dbcAMP treatment, it is difficult to determine whether or not $\alpha$ GAP slows down later stages of axonal elongation.

The localization of GAP-43 in the neurites of cultured cells during the most active phase of outgrowth corresponds to the situation observed in vivo, where the protein is densely concentrated along elongating axons (McGuire et al., 1988; Meiri et al., 1988; Moya et al., 1989; Dani et al., 1990; Goslin et al., 1990b). As neural development proceeds, the protein becomes less concentrated in the proximal portions of the axon and appears only in more distal segments, that is the growth cone and developing synapses (McGuire et al., 1988; Meiri et al., 1988; Moya et al., 1989; Dani et al., 1990). In much of the brain, this stage also lasts only briefly before levels of the protein in the neuropil begin to decline (Jacobson et al., 1986; McGuire et al., 1988; Dani et al., 1990). However, unlike neurons growing in vivo, levels of GAP-43 are high in the perikarya of NB2a/d1 and other neuroblastoma cell lines (Megerian et al., 1989) even prior to axonal neuritogenesis. Because cycloheximide fails to disrupt the outgrowth and appearance of GAP-43 in neurites, it would seem that these events involve translocation of proteins from the preexisting perikaryal pools and do not require novel protein synthesis (Goslin et al., 1990a).

Axogenesis is unquestionably a very complex phenomenon, involving the coordinate action of multiple factors acting on the expression and modification of numerous cellular constituents. Our results indicate that at least one of these constituents, the growth-associated phosphoprotein GAP-43, is essential for axonal elongation to occur. However, it is also clear that the expression of this protein in NB2a/d1 is not sufficient to induce neurite outgrowth, and that other cellular changes are required for this process. For example, disruption of the submembrane actin network or altering membrane adhesiveness and the availability of cytoskeletal precursors induces rapid neurite outgrowth in NB2a/dl cells (Shea, 1990), whereas inhibiting microtubule polymerization prevents these changes from occurring (Shea, 1990; Shea et al., 1991b). The identification of GAP-43 as one of the critical constituents in axogenesis is one step in understanding the complex orchestration of molecular events that underlie the development of neuronal circuitry.

\section{References}

Alexander KA, Cimler BM, Meier KE, Storm DR (1987) Regulation of calmodulin binding to P-57. J Biol Chem 263:7544-7549.

Benowitz LI, Routtenberg A (1987) A membrane phosphoprotein associated with neural development, axonal regeneration, phospho- 
lipid metabolism, and synaptic plasticity. Trends Neurosci 10:527532.

Benowitz LI, Apostolides PJ, Perrone-Bizzozero NI, Finklestein SP, Zwiers H (1988) Anatomical distribution of the growth-associated protein GAP-43/B-50 in the adult rat brain. J Neurosci 8:339-352.

Benowitz LI, Rodriguez WR, Neve RL (1990) The pattern of GAP$43 \mathrm{immunostaining} \mathrm{changes} \mathrm{in} \mathrm{the} \mathrm{rat} \mathrm{hippocampal} \mathrm{formation} \mathrm{during}$ reactive synaptogenesis. Mol Brain Res 8:17-23.

Dani JW, Armstrong DM, Benowitz LI (1990) Mapping the development of the rat brain by GAP-43. Neuroscience 40:277-287.

Dekker LV, DeGraan PNE, Oestreicher AB, Versteeg DHG, Gispen WH (1989) Inhibition of noradrenaline release by antibodies to B-50 (GAP-43). Nature 342:74-76.

Fischer I, Shea TB (1991) Differential appearance of extensively phosphorylated forms of the high molecular weight neurofilament protein in regions of mouse brain during postnatal development. J Neuroimmunol 31:73-81.

Freeman JJ, Lettes AA, Costello B (1988) Possible role of GAP-43 in calcium regulation/transmitter release. Soc Neurosci Abstr 14:1126

Gispen WH, Leunissen LM, Oestreicher AB, Verkleij AJ, Zwiers H (1985) Presynaptic localization of B-50 phosphoprotein: the (ACTH)sensitive protein kinase substrate involved in rat brain polyphosphoinositide metabolism. Brain Res 328:381-385.

Gordon-Weeks PR (1989) GAP-43: what does it do in the growth cone? Trends Neurosci 12:363-365.

Goslin K, Birgbauer E, Banker G, Solomon F (1990a) The role of the cytoskeleton in organizing growth cones: a microfilament-associated growth cone component depends upon microtubules for its localization. J Cell Biol 109:1621-1631.

Goslin K, Schreyer DJ, Skene JHP, Banker G (1990b) Changes in the distribution of GAP-43 during the development of neuronal polarity. J Neurosci 10:588-602.

Jacobson RD, Virag I, Skene JHP (1986) A protein associated with axon growth, GAP-43, is widely distributed and developmentally regulated in rat CNS. J Neurosci 6:1843-1855.

Jolles J, Zwiers H, Van Dongen CJ, Schotman P, Wirtz KWA, Gispen WH (1980) Modulation of brain phosphoinositide metabolism by ACTH-sensitive protein. Nature 286:623-625.

Lovinger DM, Akers RF, Nelson RB, Barnes CA, McNaughton BL, Routtenberg A (1985) A selective increase in phosphorylation of protein $F 1$, a protein kinase $C$ substrate, directly related to three day growth of long term synaptic development. Brain Res 343:137-143.

McGuire CB, Snipes GJ, Norden JJ (1988) Light-microscopic immunolocalization of the growth-associated protein GAP-43 in the developing brain. Dev Brain Res 41:277-291.

Megerian JT, Sullivan JP, Klein WL (1989) GAP-43 expression without neurite extension. Soc Neurosci Abstr 15:574.

Meiri KF, Willard M, Johnson MI (1988) Growth-associated protein,
GAP-43, a polypeptide that is induced when neurons extend axons, is a component of growth cones and corresponds to pp46, a major polypeptide of a subcellular fraction enriched in growth cones. J Neurosci 8:2571-2581.

Moya KL, Jhaveri S, Schneider GE, Benowitz LI (1989) Immunohistochemical localization of GAP-43 in the developing hamster retinofugal pathway. J Comp Neurol 288:51-58.

Nelson RB, Friedman DP, O'Neill JB, Mishkin M, Routtenberg A (1987) Gradients of protein kinase C substrate phosphorylation in primate visual system peak in visual memory storage areas. Brain Res 416:387-392.

Neve RL, Finch EA, Bird ED, Benowitz LI (1988) The growth-associated protein GAP-43 (B-50, F1) is expressed selectively in associative regions of the adult human brain. Proc Natl Acad Sci USA $85: 3638-3642$.

Nomura S, Kamiya T, Oshi M (1986) A procedure to introduce protein molecules into living mammalian cells. Exp Cell Res 163:434-444.

Perrone-Bizzozero NI, Finklestein SP, Benowitz LI (1986) Synthesis of a growth-associated protein by embryonic rat cerebrocortical neurons in vitro. J Neurosci 6:3721-3730.

Shea TB (1990) Neuritogenesis in mouse NB2a/d1 neuroblastoma cells: triggering by calcium influx and involvement of actin and tubulin dynamics. Cell Biol Int Rep 14:967-979.

Shea TB, Beermann ML (1991) A method for phospholipid-mediated delivery of specific antibodies into adherent cells. Biotechniques, in press.

Shea TB, Fischer I, Sapirstein VS (1985) Effect of retinoic acid on morphologic differentiation of mouse NB2a neuroblastoma in culture. Dev Brain Res 21:307-314.

Shea TB, Sihag RK, Nixon RA (1988) Neurofilament triplet proteins in NB2a/dl neuroblastoma: posttranslational modification and incorporation into the cytoskeleton during differentiation. Dev Brain Res 43:97-109.

Shea TB, Beermann ML, Nixon RA (1991a) Multiple proteases regulate neurite outgrowth in NB2a/dl neuroblastoma. J Neurochem, in press.

Shea TB, Perrone-Bizzozero NI, Beermann ML, Benowitz LI (1991b) Intracellular GAP-43 antibodies arrest axonal outgrowth. Trans Am Soc Neurochem 22, in press.

Skene JHP (1989) Axonal growth-associated proteins. Annu Rev Neurosci 12:127-156.

Yankner BA, Benowitz LI, Villa-Komaroff L, Neve RL (1990) Transfection of PC12 cells with the human GAP-43 gene: effects on neurite outgrowth and regeneration. Mol Brain Res 7:39-44.

Zuber MX, Goodman DW, Karns LR, Fishman MC (1989) The neuronal growth-associated protein GAP-43 induces filopodia in nonneuronal cells. Science 244:1193-1195. 